\title{
The Evidence Based Efficacy of Sublingual Immunotherapy for Allergic Rhinitis, which is the Most Appropriate Estimate?
}

\section{Incorvaia ${ }^{1 *}$, E Makri $^{1}$ and $E$ Ridolo ${ }^{2}$}

${ }^{1}$ Allergy, Cardiac/Pulmonary Rehabilitation, ASST Gaetano Pini/CTO, Milan, Italy

${ }^{2}$ Department of Clinical and Experimental Medicine, University of Parma, Italy

*Corresponding author: Cristoforo Incorvaia, Cardiac and Pulmonary Rehabilitation, ASST Gaetano Pini/CTO, Via Bignami, 20126 Milan, Italy, Tel: +390257993289; Fax: +390257993589; E-mail: cristoforo.incorvaia@gmail.com

Received date: December 24, 2016; Accepted date: December 25, 2016; Published date: December 31, 2016

Copyright: $\odot 2016$ Incorvaia C, et al. This is an open-access article distributed under the terms of the Creative Commons Attribution License, which permits unrestricted use, distribution, and reproduction in any medium, provided the original author and source are credited.

\section{Editorial}

Meta-analysis was introduced to increase the statistical reliability of a treatment when only studies including a small number of patients were available. Concerning sublingual immunotherapy (SLIT), metaanalysis was of pivotal importance in demonstrating its efficacy and thus defining SLIT as a true option to conventional, injective immunotherapy. However, in recent years the development of pharmaceutical quality SLIT products, and the consequent need to fulfill the requirements of regulatory Agencies, resulted in a number of trials including a large number of patients (this defining them as "big trials"), that make superfluous and inappropriate to perform metaanalyses.

Sublingual immunotherapy (SLIT) is acknowledged as an effective treatment of allergic rhinitis (AR), that is achieved by its capacity to work on the causes of allergy and to modify the natural history of the disease [1,2]. Clinically, the first evidence was apparent with the systematic review and meta-analysis by Wilson et al. [3] that was followed by a number of other meta-analyses, as globally evaluated by Compalati et al. [4]. Meta-analyses were essential because most trials investigating the efficacy of SLIT included small populations of patients and this prevents a statistical robustness able to provide reliable observations. Instead, a meta-analysis combines the results of multiple studies to increase the statistical power and improves the estimate of the size of the treatment effect, as assessed by the main parameter of the standardized mean difference (SMD) of the included studies results [5]. AR induced by grass pollen has high prevalence the worldwide; therefore, the efficacy of SLIT on such allergy is of particular importance. As shown by meta-analyses, the clinical benefit with SLIT is, as previously observed with subcutaneous immunotherapy, dose-dependent. In fact, the efficacy was clearly higher in subjects receiving a monthly dose from 275 to $600 \mathrm{mcg}$ compared with subjects receiving less than $275 \mathrm{mcg}$ [6].

Indeed, the need to fulfill the requirements of the European Medicine Agency (EMA) for optimal quality of grass pollen tablets was met by the performance of the so called "big trials" including large number of patients $[7,8]$. In particular, the trial with the Phleum pratense tablet included 855 participants [7] and the trial with the 5grass pollen tablet included 628 participants [8]. In addition, both products demonstrated persistent efficacy in long-term studies $[9,10]$. The approval by EMA of these standardized, pharmaceutical quality products was followed by their acceptation by the regulatory agencies in Canada, USA and Italy, where the Agenzia Italiana del Farmaco (AIFA) supported the full-reimbursement for the grass tablets in patients with grass pollen-induced AR [11].
Surprisingly, in front of such full evidence, further recent metaanalyses on SLIT for grass-pollen AR including the big trials questioned its efficacy [12]. Actually, flaws are often present in such meta-analyses including incorrect selection of trials, inappropriate use of evaluation parameters for the analysis, and incongruous analyses. In fact, meta-analysis does not fit with any application. For example, it was demonstrated that a meta-analysis of several small studies does not predict the results of a single large study that stays as gold standard to assess the efficacy and safety of a treatment. Actually, positive and negative predictive value of the meta-analyses was lower than $70 \%$ and the difference in point estimates between the randomized trials and the meta-analyses was statistically significant for only 5 of 40 comparisons $[13,14]$. The misuse of meta-analyses for SLIT was already noted by Milgrom [15] and a falling scientific interest for meta-analysis on SLIT emerged from the number of citations that strongly decreased in the latest years [12].

This lesson should be learned in view of the recent big trials on the house dust mite tablets for SLIT conducted in Europe [16,17], USA [18], and Japan [19], whose efficacy data do not need meta-analysis to confirm for mite allergy that same outcome achieved for grass pollen allergy, when new generation, pharmaceutical quality product for immunotherapy are used.

\section{References}

1. Scadding G, Durham S (2009) Mechanisms of sublingual immunotherapy. J Asthma 46: 322-334.

2. Incorvaia C, Moingeon P, Buttafava S, Frati F (2014) Focusing the mechanism of action to dissect the different treatments of respiratory allergy. Expert Rev Clin Immunol 11: 1005-1013.

3. Wilson DR, Lima MT, Durham SR (2005) Sublingual immunotherapy for allergic rhinitis: systematic review and meta-analysis. Allergy 60: 4-12.

4. Compalati E, Penagos M, Tarantini F, Passalacqua G, Canonica GW, et al. (2009) Specific immunotherapy for respiratory allergy: state of the art according to current meta-analyses. Ann Allergy Asthma Immunol 102: $22-28$.

5. O'Rourke K (2007) An historical perspective on meta-analysis: dealing quantitatively with varying study results. J R Soc Med 100: 579-582.

6. Frati F, Incorvaia C, Scurati S, Sensi L, Marcucci F, et al. (2011) Dosedependence of sublingual immunotherapy shown by meta-analysis. J Allergy Clin Immunol 127: 1076-1077.

7. Durham SR, Yang WH, Pedersen MR, Johansen N, Rak S, et al. (2006) Sublingual immunotherapy with once daily grass allergen tablet: a randomized controlled trial in seasonal allergic rhinoconjunctivitis. J Allergy Clin Immunol 117: 802-809.

8. Didier A, Malling HJ, Worm M, Horak F, Jager S, et al. (2007) Optimal dose, efficacy, and safety of once daily sublingual immunotherapy with a 5- 
Citation: Incorvaia C, Makri E, Ridolo E (2016) The Evidence Based Efficacy of Sublingual Immunotherapy for Allergic Rhinitis, which is the Most Appropriate Estimate?. J Allergy Ther 7: e118. doi:10.4172/2155-6121.1000e118

Page 2 of 2

grass pollen tablet for seasonal allergic rhinitis. J Allergy Clin Immuno 120: $1338-1345$

9. Durham SR, Emminger W, Kapp A, De Monchy JG, Rak S, et al. (2012) SQstandardized sublingual grass immunotherapy: confirmation of modification 2 years after 3 years of treatment in a randomized trial. J Allergy Clin Immunol 129: 717-725.

10. Didier A, Malling HJ, Worm M, Horak F, Sussman G, et al. (2013) Posttreatment efficacy of discontinuous treatment with 300IR 5-grass pollen sublingual tablet in adults with grass pollen-induced allergic rhincoconjunctivitis. Clin Exp Allergy 43: 568-577.

11. Ciprandi G (2015) A major step forward for sublingual immunotherapy: the quality of 5-grass pollen tablet is recognized also in Italy. J Asthma Allergy 8: 25-27.

12. Ridolo E, Incorvaia C, Gritti BL, Passalacqua G (2017) The current overuse and misuse of meta-analyses on sublingual immunotherapy: the case of grass pollen allergy. Curr Opin Allergy Clin Immunol 17: 12-16.

13. Villar J, Carroli G, Belizan JM (1995) Predictive ability of meta-analysis of randomised controlled trials. Lancet 345: 772-776.

14. LeLorier J, Gregoire G, Benhaddad A, Lapierre J, Derderian F, et al. (1997) Discrepancies between meta-analyses and subsequent large randomized, controlled trials. N Engl J Med 337: 536-542.
15. Milgrom H, Tran ZV (2009) Sublingual immunotherapy, meta-analysis, and knowledge in the age of information. J Allergy Clin Immunol 124: 162-163.

16. Bergmann KC, Demoly P, Worm M, Fokkens WJ, Carrillo T, et al. (2014) Efficacy and safety of sublingual tablets of house dust mite allergen extracts in adults with allergic rhinitis. J Allergy Clin Immunol 133: 1608-1614.

17. Mosbech H, Canonica GW, Backer V, De Blay F, Klimek L, et al. (2015) SQ house dust mite sunblingually administered immunotherapy tablet (ALK) improves allergic rhinitis in patients with house dust mite allergic asthma and rhinitis symptoms. Ann Allergy Asthma Immunol 114: 134-140.

18. Nolte H, Bernstein DI, Nelson HS, Kleine-Tebbe J, Sussman GL, et al. (2016) Efficacy of house dust mite sublingual immunotherapy tablet in North American adolescents and adults in a randomized, placebocontrolled trial. J Allergy Clin Immunol 138: 1631-1638.

19. Okubo K, Masuyama K, Imai T, Okamiya K, Stage BS, et al. (2016) Efficacy and safety of the SQ house dust mite sublingual immunotherapy tablet in Japanese adults and adolescents with house dust mite-induced allergic rhinitis. J Allergy Clin Immunol 6749: 31294-31295. 